\title{
Exact Solutions for the Response of Purely Nonlinear Oscillators: Overview
}

\author{
L. Cveticanin ${ }^{1}$, I. Kovacic ${ }^{1^{*}}$ \\ ${ }^{1}$ University of Novi Sad, Faculty of Technical Sciences, Centre of Excellence for Vibro \\ Acoustic Systems and Signal Processing CEVAS \\ e-mail: cveticanin@uns.ac.rs \\ e-mail: ivanakov@uns.ac.rs \\ *corresponding author
}

\begin{abstract}
This article provides an overview of the exact closed-form solutions for purely nonlinear oscillators. These solutions comprise the period of vibration and free and forced responses for one-degree-of-freedom systems. The use of special function for this purpose is demonstrated which includes: beta function, gamma function, hypergeometric function, Ateb function, Jacobi amplitude and Jacobi elliptic function.
\end{abstract}

Keywords: purely nonlinear oscillators, free response, forced response, Ateb functions, Jacobi elliptic functions

\section{Introduction}

The real world contains a diversity of nonlinear systems exhibiting oscillatory motion. These systems are usually modelled as oscillators with strong nonlinearity. This nonlinearity is very often much stronger than the linearity or even the oscillator is with the so-called 'pure/true nonlinearity'. This pure nonlinearity corresponds to the case when the elastic/restoring force is the function of nonlinear deflection described by a binomial of any real power higher than unity, which can be represented as follows:

$$
F(x)=-x|x|^{\alpha-1}, \quad \alpha \geq 1 .
$$

Such nonlinearity is caused by the geometry of the system, mainly by material properties. It has been proven experimentally that the stress-strain relationship is purely nonlinear for many materials: some aircraft materials, such as aluminium, titanium, etc., (Prathap and Varadan 1976), copper and copper alloys (Lo and Gupta 1978), aluminium alloys and annealed copper (Lewis and Monasa 1982), wood (Haslach 1985), hydrophilic polymers (Haslach 1992), composites (Chen and Gibson 1998), polyurethane foam (Patten et al. 1998), ceramic materials (Colm and Clark 1988), etc. The mathematical model for these oscillators is a second order strongly nonlinear ordinary differential equation. Its exact closed form analytical solution is not always attainable. In this paper, those purely nonlinear differential equations for which the exact solution or its properties are known are considered and overviewed. 


\section{Period of vibration}

One of the main properties of each oscillator is its frequency and period of vibration. In this section, it is shown that the exact analytical expression of the frequency of vibration exists for purely nonlinear oscillators. This expression is of special interest as it gives the possibility to analyse how the frequency property of the oscillator is influenced by the parameters of the system and also initial conditions (for free vibrations) and the excitation force (if it acts). Two types of oscillators are considered: a) free purely nonlinear oscillator and b) purely nonlinear oscillator with a constant excitation force. The mathematical model for purely nonlinear oscillators is

$$
\ddot{x}+c_{\alpha}^{2} x|x|^{\alpha-1}=0
$$

with the initial conditions

$$
x(0)=A, \quad \dot{x}(0)=0 .
$$

For the oscillators with a constant excitation force $F_{0}$ the equation of motion has the form

$$
\ddot{x}+c_{\alpha}^{2} x|x|^{\alpha-1}=F_{0},
$$

with the initial conditions

$$
x(0)=0, \quad \dot{x}(0)=0,
$$

where $\alpha \geq 1$ is the power/order of nonlinearity (a real number of integer or non-integer type); $c_{\alpha}^{2}$ is the coefficient of the nonlinear term and $A$ is the initial amplitude of vibration. The exact analytical expression for the period of vibration is obtained using the corresponding first integrals of Eqs. (2) and (4).

\subsection{Free truly nonlinear oscillator}

Integrating Eq. (2) and using the initial conditions (3), the first integral of the energy type is obtained

$$
\frac{\dot{x}^{2}}{2}+\frac{c_{\alpha}^{2}}{\alpha+1}|x|^{\alpha+1}=\frac{c_{\alpha}^{2}}{\alpha+1}|A|^{\alpha+1} .
$$

Being both addends on the left nonnegative, the associated phase paths represent a generalized Lamé superellipse in the $x-\dot{x}$ phase plane. There is a single equilibrium point $x=\dot{x}=0$ such that it is a centre. Therefore the solutions of Eq. (2) are periodic in time (Gottlieb 2003) with the period

$$
T=4 \int_{0}^{A} \frac{d x}{|\dot{x}|}=4 \sqrt{\frac{\alpha+1}{2 c_{\alpha}^{2}}} \int_{0}^{A} \frac{d x}{\sqrt{|A|^{\alpha+1}-|x|^{\alpha+1}}} .
$$

Substituting the new variable $|x|=|A||u|^{1 /(\alpha+1)}$ into Eq. (7), the transformed version of this period is

$$
T=\frac{4|A|^{(1-\alpha) / 2}}{c_{\alpha} \sqrt{2(\alpha+1)}} \int_{0}^{1}(1-|u|)^{-1 / 2} u^{-\alpha /(\alpha+1)} d u .
$$


Introducing the Euler beta function $\mathrm{B}(m, n)$ (see, Rosenberg, 1966)

$$
B(m, n)=\int_{0}^{1}(1-|u|)^{n-1} u^{m-1} d u,
$$

the relation (8) can be rewritten as follows

$$
T=\frac{4|A|^{(1-\alpha) / 2}}{c_{\alpha} \sqrt{2(\alpha+1)}} \mathrm{B}\left(\frac{1}{\alpha+1}, \frac{1}{2}\right) .
$$

Due to the relationship

$$
\mathrm{B}(m, n)=\frac{\Gamma(m) \Gamma(n)}{\Gamma(m+n)},
$$

the exact period is

$$
T=\frac{4|A|^{(1-\alpha) / 2}}{c_{\alpha} \sqrt{2(\alpha+1)}} \frac{\Gamma\left(\frac{1}{\alpha+1}\right) \Gamma\left(\frac{1}{2}\right)}{\Gamma\left(\frac{3+\alpha}{2(\alpha+1)}\right)},
$$

where $\Gamma$ is the Euler gamma function (Gradshtein and Rjizhik 1971).

Using $\Gamma\left(\frac{1}{2}\right)=\sqrt{\pi}$ (Gradshtein and Rjizhik 1971), the period expression is finally (Cveticanin 2009)

$$
T=\frac{1}{c_{\alpha} \mid A^{(\alpha-1) / 2}} \frac{2 \sqrt{2 \pi}}{\sqrt{(\alpha+1)}} \frac{\Gamma\left(\frac{1}{\alpha+1}\right)}{\Gamma\left(\frac{3+\alpha}{2(\alpha+1)}\right)} .
$$

The period of vibration for various powers of nonlinearity is shown in Table 1.

\begin{tabular}{|c|c|c|}
\hline$\alpha$ & $T$ & $\omega=\frac{2 \pi}{T}$ \\
\hline 1 & $\frac{6.2832}{c_{\alpha}|A|^{0}}$ & $c_{\alpha}|A|^{0}$ \\
\hline $4 / 3$ & $\frac{6.4832}{c_{\alpha}|A|^{1 / 6}}$ & $0.96915 c_{\alpha}|A|^{1 / 6}$ \\
\hline $3 / 2$ & $\frac{6.5814}{c_{\alpha}|A|^{1 / 4}}$ & $0.95469 c_{\alpha}|A|^{1 / 4}$ \\
\hline $5 / 3$ & $\frac{6.6785}{c_{\alpha}|A|^{1 / 3}}$ & $0.94081 c_{\alpha}|A|^{1 / 3}$ \\
\hline 2 & $\frac{6.8693}{c_{\alpha}|A|^{1 / 2}}$ & $0.91468 c_{\alpha}|A|^{1 / 2}$ \\
\hline 3 & $\frac{7.4163}{c_{\alpha}|A|^{1}}$ & $0.84721 c_{\alpha}|A|^{1}$ \\
\hline 5 & $\frac{8.4196}{c_{\alpha}|A|^{2}}$ & $0.74625 c_{\alpha}|A|^{2}$ \\
\hline
\end{tabular}

Table 1. Period of vibration and the related frequency as a function of the power of nonlinearity 
The result (13) was also reported by Rosenberg (1963). In general, the period of vibration for $x(t)=x(t+T)$ is asynchronous.

Analysing the obtained values and Eq. (13), it can be concluded:

a) The period of vibration is the linear function of the stiffness parameter $\left(1 / c_{\alpha}\right)$.

b) The period of vibration depends on the initial amplitude: for the same power of nonlinearity, the period is longer for a smaller initial amplitude $A$.

c) The power of nonlinearity affects the period of vibration via the initial amplitude: the higher the power of nonlinearity, the smaller the order of initial amplitude that affects the period of vibration $\left(|A|^{-(\alpha-1) / 2}\right)$.

d) Purely nonlinear oscillators have the same period of vibration as the linear one if the initial amplitude has a special value

$$
|A|^{(\alpha-1) / 2}=\frac{\sqrt{2}}{\sqrt{\pi(\alpha+1)}} \frac{\Gamma\left(\frac{1}{\alpha+1}\right)}{\Gamma\left(\frac{3+\alpha}{2(\alpha+1)}\right)} .
$$

e) For $A=1$, the period of vibration increases as the power of nonlinearity increases.

\subsection{Truly nonlinear oscillator with constant excitation}

The first integral of Eq. (4) for the initial conditions (5) has the following form:

$$
\frac{\dot{x}^{2}}{2}+x\left(c_{\alpha}^{2} \frac{|x|^{\alpha}}{\alpha+1}-F_{0}\right)=0 .
$$

Assuming that the direction of excitation is constant and does not depend on motion direction, the expression (14) is rewritten in the form:

$$
\frac{\dot{x}^{2}}{2} \pm|x|\left(c_{\alpha}^{2} \frac{|x|^{\alpha}}{\alpha+1}-F_{0}\right)=0,
$$

where the upper sign holds for $x \geq 0$ and the other one for $x \leq 0$. Due to equality of the curves, the analysis is done only for one of them. The $x-\dot{x}$ curves which correspond to Eq. (15), when $x \geq 0$ and $x \leq 0$, are closed ones. Thus, the solution of Eq. (4) is periodic.

To calculate the period of vibration, Eq. (15) is rewritten as follows:

$$
\frac{d x}{d t}=\sqrt{2 F_{0}|x|-2 c_{\alpha}^{2} \frac{|x|^{\alpha+1}}{\alpha+1}},
$$

i.e.

$$
\frac{d x}{d t}=\sqrt{2 F_{0}|x|} \sqrt{1-\frac{c_{\alpha}^{2}}{F_{0}} \frac{|x|^{\alpha}}{\alpha+1}} .
$$

For mathematical convenience, a new variable is introduced:

$$
u=\frac{c_{\alpha}^{2}}{F_{0}} \frac{|x|^{\alpha}}{\alpha+1},
$$


with the time derivative:

$$
\frac{d u}{d t}=\frac{c_{\alpha}^{2}}{F_{0}} \frac{\alpha}{\alpha+1}|x|^{\alpha-1} \frac{d x}{d t} .
$$

Substituting Eqs. (18) and (19) into Eq. (16) and separating the variables, the following expression is obtained:

$$
d t=\frac{1}{\alpha u \sqrt{2 F_{0}(1-u)}}\left(\frac{F_{0}(\alpha+1) u}{c_{\alpha}^{2}}\right)^{1 / 2 \alpha} d u .
$$

After suitable transformation and integration, the half-period of vibration is found to be:

$$
\frac{T}{2}=\frac{1}{\alpha \sqrt{2 F_{0}}}\left(\frac{F_{0}(\alpha+1)}{c_{\alpha}^{2}}\right)^{1 / 2 \alpha} \int_{0}^{1} u^{\frac{1-2 \alpha}{2 \alpha}}(1-u)^{-1 / 2} d u .
$$

According to the definition of the beta function:

$$
\int_{0}^{1} u^{\frac{1}{2 \alpha}-1}(1-u)^{1 / 2-1} d u=\mathrm{B}\left(\frac{1}{2 \alpha}, \frac{1}{2}\right)
$$

the period of vibration is:

$$
T=\frac{2}{\alpha \sqrt{2 F_{0}}}\left(\frac{F_{0}(\alpha+1)}{c_{\alpha}^{2}}\right)^{1 / 2 \alpha} \mathrm{B}\left(\frac{1}{2 \alpha}, \frac{1}{2}\right) .
$$

It is recommended to rewrite the expression (23) by using the gamma function, which is more convenient. Introducing the transformation (11), the period of vibration is (Cveticanin 2011):

$$
T=\frac{\sqrt{2}}{\alpha F_{0}^{(\alpha-1) / 2 \alpha}}\left(\frac{(\alpha+1)}{c_{\alpha}^{2}}\right)^{1 / 2 \alpha} \frac{\Gamma\left(\frac{1}{2 \alpha}\right) \Gamma\left(\frac{1}{2}\right)}{\Gamma\left(\frac{1+\alpha}{2 \alpha}\right)} .
$$

Based on the exact period of vibration (24), the exact angular frequency is:

$$
\omega=\frac{2 \pi}{T}=\sqrt{2} \pi \alpha F_{0}^{(\alpha-1) / 2 \alpha}\left(\frac{c_{\alpha}^{2}}{\alpha+1}\right)^{1 / 2 \alpha} \frac{\Gamma\left(\frac{1+\alpha}{2 \alpha}\right)}{\Gamma\left(\frac{1}{2 \alpha}\right) \Gamma\left(\frac{1}{2}\right)} .
$$

Analysing the relation (24), it can be concluded:

a) For higher values of the parameter $F_{0}$, the period of vibrations is shorter. If $F_{0}$ tends to infinity, the period tends to zero. If $F_{0}$ is zero, the period of vibration is infinitely large and no oscillatory motion exists.

b) For the linear oscillator ( $\alpha=1$ ), the period of vibration does not depend on the excitation magnitude $F_{0}$ and has the well-known value

$$
T=\frac{2}{c_{1}} \mathrm{~B}\left(\frac{1}{2}, \frac{1}{2}\right)=\frac{2 \pi}{c_{1}},
$$

as $\Gamma(1 / 2)=\sqrt{\pi}$ and $\Gamma(1)=1$. The frequency of vibration is: 


$$
\omega=\frac{2 \pi}{T}=c_{1}
$$

c) The coefficient of nonlinearity $c_{\alpha}$ also has a significant influence on the period of vibration. Its influence varies. Given $T=f\left(F_{0}, \alpha\right)\left(c_{\alpha}\right)^{-1 / \alpha}$, the following holds: for the linear oscillator ( $\alpha=1$ ), the angular frequency is proportional to $c_{1}$; for higher powers of nonlinearity, the influence of $c_{\alpha}$ on the period of vibration is smaller and for $\alpha$ approaching infinity, the influence of the parameter $c_{\alpha}$ disappears.

\section{Free response}

\subsection{Exact solution for motion}

Let us rewrite Eq. (6) as follows:

$$
\dot{x}^{2}+\frac{2 c_{\alpha}^{2}}{\alpha+1}|x|^{\alpha+1}=\frac{2 c_{\alpha}^{2}}{\alpha+1} A^{\alpha+1}, \quad A>0,
$$

which yields

$$
\dot{x}= \pm K \sqrt{1-\left(\frac{|x|}{A}\right)^{\alpha+1}}, \quad K=\frac{\sqrt{2}\left|c_{\alpha}\right| A^{(\alpha+1) / 2}}{\sqrt{\alpha+1}} .
$$

Now, Eq. (2) can be solved analytically (Cveticanin and Pogany 2012). Let us choose the positive right-hand side expression in Eq. (2). It will be:

$$
L=\int \frac{d x}{\sqrt{1-\left(\frac{|x|}{A}\right)^{\alpha+1}}}=K t+C,
$$

where $C$ denotes the integration constant. Expanding the integrand in $L$ into a binomial series and then integrating it twice, we conclude:

$$
L=\int \sum_{n=0}^{\infty}(-1)^{n}\left(\begin{array}{c}
-\frac{1}{2} \\
n
\end{array}\right)\left(\frac{|x|}{A}\right)^{(\alpha+1) n} d x=A \sum_{n=0}^{\infty}\left(\begin{array}{c}
-\frac{1}{2} \\
n
\end{array}\right) \frac{1}{(\alpha+1) n+1}\left(\frac{|x|}{A}\right)^{(\alpha+1) n+1} .
$$

Employing the Pochhammer symbol $(a)_{n}=a(a+1) \cdots(a+n-1), n \in \mathrm{N}$ mutatis mutandis

$$
\left(\begin{array}{c}
-\frac{1}{2} \\
n
\end{array}\right)=(-1)^{n} \frac{\left(\frac{1}{2}\right)_{n}}{n !}
$$

and

$$
\frac{1}{(\alpha+1) n+1}=\frac{\frac{1}{\alpha+1}}{n+\frac{1}{\alpha+1}}=\frac{\left(\frac{1}{\alpha+1}\right)_{n}}{\left(\frac{\alpha+2}{\alpha+1}\right)_{n}}
$$

Then, 


$$
L=|x| \sum_{n=0}^{\infty} \frac{\left(\frac{1}{2}\right)_{n}\left(\frac{1}{\alpha+1}\right)_{n}}{\left(\frac{\alpha+2}{\alpha+1}\right)_{n} n !}\left(\frac{|x|}{A}\right)^{(\alpha+1) n}=|x|_{2} F_{1}\left[\begin{array}{c}
\frac{1}{2}, \frac{1}{\alpha+1} \\
\frac{\alpha+2}{\alpha+1}
\end{array} \mid\left(\frac{|x|}{A}\right)^{\alpha+1}\right] .
$$

Now, by using the formula that connects the Gaussian hypergeometric ${ }_{2} F_{1}$ and the incomplete Beta function $\mathrm{B}_{z}$ (see Web1 and Web2):

$$
{ }_{2} F_{1}\left[\begin{array}{c}
a, 1-b \\
a+1
\end{array} \mid z\right]=\frac{a}{z^{a}} \mathrm{~B}_{z}(a, b), \quad|z|<1,
$$

and letting

$$
a=\frac{1}{\alpha+1}, \quad b=\frac{1}{2}
$$

we get:

$$
\mathrm{B}_{\left(\frac{|x|}{A}\right)^{\alpha+1}}\left(\frac{1}{\alpha+1}, \frac{1}{2}\right)=\sqrt{2(\alpha+1)}\left|c_{\alpha}\right| A^{(\alpha-1) / 2} t+C .
$$

Finally, the initial condition $x(0)=A$ gives:

$$
\begin{aligned}
& \frac{(\alpha+1)|x|}{A}{ }_{2} F_{1}\left[\begin{array}{l}
\frac{1}{\alpha+1}, \frac{1}{2} \\
1+\frac{1}{\alpha+1}
\end{array} \mid\left(\frac{|x|}{A}\right)^{\alpha+1}\right]=\mathrm{B}_{\left(\frac{|x|}{A}\right)^{\alpha+1}}\left(\frac{1}{\alpha+1}, \frac{1}{2}\right) \\
& =\mathrm{B}\left(\frac{1}{\alpha+1}, \frac{1}{2}\right)+\sqrt{2(\alpha+1)}\left|c_{\alpha}\right| A^{(\alpha-1) / 2} t \text {. }
\end{aligned}
$$

This relation is the main tool in determining the explicit solution of Cauchy problem (2) with (3).

In his classical paper from 1963, Rosenberg introduced the so-called periodic Atebfunctions concerning the problem of inversion of the half of the incomplete beta function

$$
z \mapsto \frac{1}{2} \mathrm{~B}_{z}(a, b)=\frac{1}{2} \int_{0}^{0 \leq x \leq 1} t^{a-1}(1-t)^{b-1} d t .
$$

Obviously, we are interested in the case $a=\frac{1}{\alpha+1}, b=\frac{1}{2}$, when the Ateb functions are in the focus of our interest as the solutions of the system of ordinary differential equations (see Senik, 1969)

$$
\begin{aligned}
\dot{v}-u^{\alpha} & =0, \\
\dot{u}+\frac{2}{\alpha+1} v & =0 .
\end{aligned}
$$

We write:

$$
v(z)=\operatorname{sa}(1, \alpha, z), \quad u(z)=\operatorname{ca}(\alpha, 1, z) .
$$

It can easily be verified that the inverse of $\frac{1}{2} \mathrm{~B}_{z}\left(\frac{1}{2}, \frac{1}{\alpha+1}\right)$ and $v(z)$ coincide on $\left[-\frac{1}{2} \Pi_{\alpha}, \frac{1}{2} \Pi_{\alpha}\right]$, where 


$$
\Pi_{\alpha}:=\mathrm{B}\left(\frac{1}{\alpha+1}, \frac{1}{2}\right) .
$$

Having in mind the following set of properties:

$$
\operatorname{sa}(1, \alpha, z)=\left\{\begin{array}{l}
-\mathrm{sa}(1, \alpha,-z) \\
\mp \mathrm{ca}\left(\alpha, 1, \frac{1}{2} \Pi_{\alpha} \pm x\right) \\
\pm \mathrm{sa}\left(1, \alpha, \Pi_{\alpha} \pm z\right) \\
\mp \mathrm{sa}\left(1, \alpha, 2 \Pi_{\alpha} \mp z\right)
\end{array}\right.
$$

we see that $\operatorname{sa}(\alpha, 1, z)$ is an odd function of $z \in R$; it is the so-called $2 \Pi_{\alpha}$-periodic sine Ateb, i.e. sa -function. In addition, the following holds (Senik 1969):

$$
\operatorname{sa}^{2}(1, \alpha, z)+\mathrm{ca}^{\alpha+1}(\alpha, 1, z)=1,
$$

and cosine Ateb, that is the $\mathrm{ca}(1, \alpha, z)$ function, is even and $2 \Pi_{\alpha}$-periodic, with the following properties (Senik 1969):

$$
\operatorname{ca}(\alpha, 1, z)=\left\{\begin{array}{l}
\operatorname{ca}(\alpha, 1,-z) \\
\operatorname{sa}\left(1, \alpha, \frac{1}{2} \Pi_{\alpha} \pm z\right) \\
-\operatorname{ca}\left(\alpha, 1, \Pi_{\alpha} \pm z\right) \\
\operatorname{ca}\left(\alpha, 1,2 \Pi_{\alpha} \pm z\right)
\end{array} .\right.
$$

By these two sets of expressions, we see that the functions sa, ca are defined on the whole range of $R$.

Now, inverting the half of the incomplete beta function in Eq. (33):

$$
\frac{1}{2} \mathrm{~B}_{\left(\frac{|x|}{A}\right)^{\alpha+1}}\left(\frac{1}{\alpha+1}, \frac{1}{2}\right)=\frac{\Pi_{\alpha}}{2}+\frac{\sqrt{\alpha+1}\left|c_{\alpha}\right|}{\sqrt{2}} A^{(\alpha-1) / 2} t,
$$

we deduce that:

$$
x(t)=A \operatorname{sa}\left(1, \alpha, \frac{\Pi_{\alpha}}{2}+\sqrt{\frac{\alpha+1}{2}}\left|c_{\alpha}\right| A^{(\alpha-1) / 2} t\right) .
$$

Having in mind the quarter-period expansion formula (39), we arrive at:

$$
x(t)=A \text { ca }\left(\alpha, 1, \sqrt{\frac{\alpha+1}{2}}\left|c_{\alpha}\right| A^{(\alpha-1) / 2} t\right), \quad t \in \mathrm{R} .
$$

By using $\operatorname{ca}(\alpha, 1,0)=1$, we see that the initial condition $x(0)=A$ is satisfied.

\subsection{Fourier series representation}

To provide an insight into the type of the response described by the Ateb function derived, a Fourier series representation is used. Since the ca-function is odd, its Fourier series comprises odd harmonics only, and it can be expressed as: 


$$
\mathrm{ca}(\alpha, 1, t)=\sum_{N=1}^{\infty} C_{2 N-1}(\alpha) \cos \left[(2 N-1) \frac{2 \pi}{T} t\right],
$$

where the Fourier coefficients $C_{2 N-1}$ depend on the parameter $\alpha$, and are defined by

$$
C_{2 N-1}(\alpha)=\frac{4}{T} \int_{0}^{T / 2} \mathrm{ca}(\alpha, 1, t) \cos \left[(2 N-1) \frac{2 \pi}{T} t\right] d t,
$$

where $T$ is the period.

To write this expression in a suitable form for further calculation, the procedure recently proposed in (Belendez et al. 2015) is utilised. As the first step, the displacement is rescaled by the initial amplitude $X=x / A$, yielding

$$
C_{2 N-1}(\alpha)=\frac{8}{T} \int_{0}^{T / 4} X(\alpha, t) \cos \left[(2 N-1) \frac{2 \pi}{T} t\right] d t .
$$

Now, to find the expression for $d t$, the first integral is composed, and the following is derived:

$$
d t=\sqrt{\frac{\alpha+1}{2 c_{\alpha}^{2}}}|A|^{(1-\alpha) / 2} \frac{d X}{\sqrt{1-|X|^{\alpha+1}}} .
$$

This expression gives the possibility to determine how $t$ depends on $X$ (noting that this holds for $X \geq 0)$ :

$$
t(X)=\sqrt{\frac{\alpha+1}{2 c_{\alpha}^{2}}}|A|^{(1-\alpha) / 2} \int_{X}^{1} \frac{d y}{\sqrt{1-y^{\alpha+1}}} .
$$

Performing some transformations, one can derive (see Belendez et al. 2015 for further details):

$$
t(X)=\sqrt{\frac{\pi}{2 c_{\alpha}^{2}(\alpha+1)}} \frac{\Gamma\left(\frac{1}{\alpha+1}\right)}{\Gamma\left(\frac{\alpha+3}{2(\alpha+1)}\right)} \mid A^{(1-\alpha) / 2} I\left(1-X^{\alpha+1}, \frac{1}{2}, \frac{1}{\alpha+1}\right),
$$

where $I$ stands for the regularized incomplete beta function.

Finally, substituting Eq. (45) into Eq. (44) as well as Eq. (47) into the argument of the cosine function in Eq. (44), one derives:

$$
C_{2 N-1}(\alpha)=\frac{2(\alpha+1) \Gamma\left(\frac{\alpha+3}{2(\alpha+1)}\right)}{\sqrt{\pi} \Gamma\left(\frac{1}{\alpha+1}\right)} \int_{0}^{1} \frac{X}{\sqrt{1-X^{\alpha+1}}} \cos \left[\frac{(2 n-1) \pi}{2} I\left(1-X^{\alpha+1}, \frac{1}{2}, \frac{1}{\alpha+1}\right)\right] d X .
$$

By using the substitution $z=1-X^{\alpha+1}$, the following expression for the Fourier coefficients is obtained:

$$
C_{2 N-1}(\alpha)=\frac{2 \Gamma\left(\frac{\alpha+3}{2(\alpha+1)}\right)}{\sqrt{\pi} \Gamma\left(\frac{1}{\alpha+1}\right)} \int_{0}^{1} \frac{(1-z)^{(1-\alpha) /(1+\alpha)}}{\sqrt{z}} \cos \left[\frac{(2 N-1) \pi}{2} I\left(z, \frac{1}{2}, \frac{1}{\alpha+1}\right)\right] d z .
$$


These values can be calculated by carrying out numerical integration. First four Fourier coefficients are calculated in this way by using Eq. (49) and are plotted in Fig. 1 as a function of the power $\alpha$. It is seen that: $C_{1}$ decreases from unity as $\alpha$ increases; $C_{3}$ and $C_{7}$ are positive; $C_{5}$ is negative for $1<\alpha<2.34$, and positive otherwise.

\subsection{Special cases}

\subsubsection{Case $\alpha=1$}

Equation (2) reduces to

$$
\ddot{x}+c_{1}^{2} x=0 .
$$

By virtue of the initial condition $x(0)=A$, Eq. (33) becomes

$$
|x|_{2} F_{1}\left[\begin{array}{c}
\frac{1}{2}, \frac{1}{2} \\
\frac{3}{2}
\end{array} \mid\left(\frac{x}{A}\right)^{2}\right]=A \arcsin \left(\frac{x}{A}\right)=A\left(\frac{\pi}{2}+\left|c_{1}\right| t\right),
$$

so that the solution for the response takes the well-known form:

$$
x(t)= \pm A \sin \left(\frac{\pi}{2}+\left|c_{1}\right| t\right)=A \cos \left(\left|c_{1}\right| t\right)
$$

a)
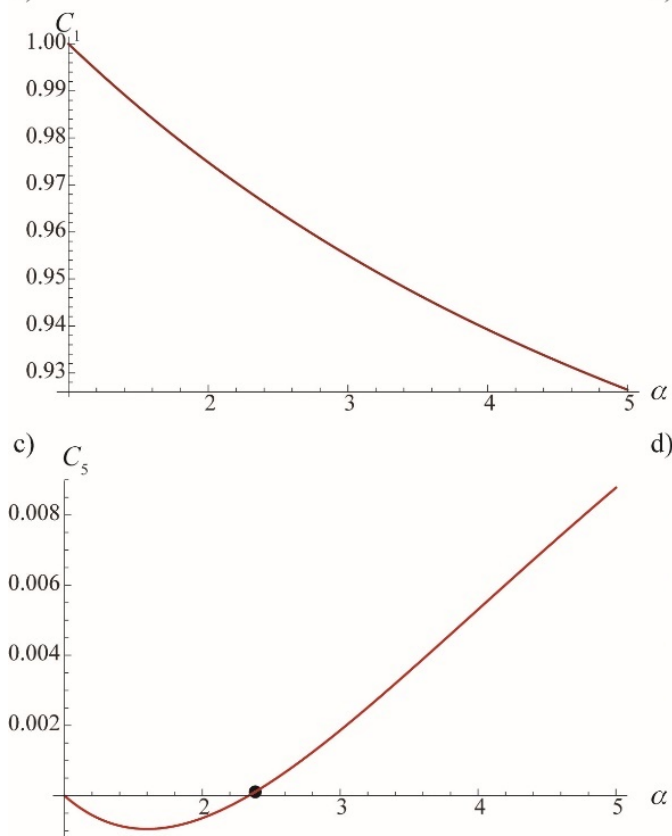

b)
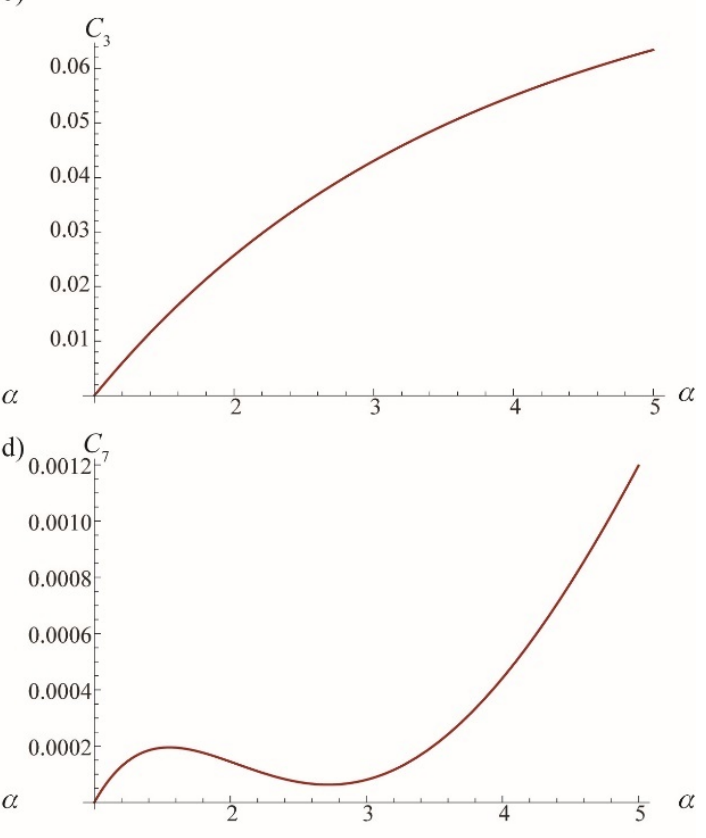

Fig. 1. Fourier coefficients given by Eq. (49) as a function of the power of nonlinearity $\alpha$ for

$$
c_{\alpha}=1, A=1: \text { a) } C_{1} \text {; b) } C_{3} \text {; c) } C_{5} \text {; d) } C_{7}
$$




\subsubsection{Case $\alpha=2$}

Equation (2) now transforms into

$$
\ddot{x}+c_{2}^{2} x|x|=0 .
$$

According to Eq. (41), the exact solution is

$$
x(t)=A c a\left(2,1, \frac{\sqrt{3}\left|c_{2}\right|}{\sqrt{2}} A^{1 / 2} t\right)
$$

where the period of the ca-function (36) is

$$
\Pi_{2}:=\mathrm{B}\left(\frac{1}{3}, \frac{1}{2}\right)=\frac{\Gamma\left(\frac{1}{3}\right) \Gamma\left(\frac{1}{2}\right)}{\Gamma\left(\frac{5}{6}\right)} .
$$

Using the frequency of the ca function (52)

$$
\Omega=\frac{\sqrt{3}\left|c_{2}\right|}{\sqrt{2}} A^{1 / 2}
$$

the period of vibration is

$$
T=\frac{2 \Pi_{2}}{\Omega}=\frac{\Gamma\left(\frac{1}{3}\right)}{\Gamma\left(\frac{5}{6}\right)} \frac{\sqrt{2 \pi}}{\sqrt{3}\left|c_{2}\right| A^{1 / 2}} .
$$

Comparing Eq. (53) with the period given by Eq. (13) for $\alpha=2$, it is seen that the results are equal (Cveticanin 2014).

By using Eq. (2), the solution given by Eq. (52) corresponding to $c_{2}=1$ and $A=1$ can be expressed as

$$
\begin{gathered}
x(t)=\mathrm{ca}\left(2,1, \sqrt{\frac{3}{2}} t\right), \\
x(t) \approx 0.97480 \cos (0.91468 t)+0.02572 \cos (2.74404 t)- \\
0.00064 \cos (4.57341 t)+0.00014 \cos (6.40277 t) .
\end{gathered}
$$

This implies that the content is such that the first harmonic dominates with $97 \%$ in the response, the third one takes around $2.5 \%$ of it, and the rest of them are much smaller. The fifth harmonic has a negative coefficient.

\subsubsection{Case $\alpha=3$}

Let us recall (Web3, Web4) that

$$
{ }_{2} F_{1}\left[\begin{array}{c}
\frac{1}{4}, \frac{1}{2} \\
\frac{5}{4}
\end{array} \mid z\right]=\frac{1}{\sqrt[4]{z}} F(\arcsin \sqrt[4]{z} \mid-1)=\frac{1}{\sqrt[4]{z}} \operatorname{sn}^{-1}(z \mid-1), \quad|z|<1,
$$

where

$$
F(z \mid m)=\int_{0}^{z=\operatorname{am}(z \mid m)} \frac{\mathrm{d} t}{\sqrt{1-m \sin ^{2} t}}, \quad \operatorname{sn}(z \mid m)=\sin \operatorname{am}(z \mid m),
$$


and $F$, am, sn denote the incomplete elliptic integral of the first kind, the Jacobi amplitude, the Jacobi elliptic sn function and $s n^{-1}$ stands for the inverse Jacobi elliptic sn functions respectively.

Thus, for $\alpha=3$ we have

$$
|x|_{2} F_{1}\left[{ }_{\frac{1}{4}}^{\frac{1}{4}, \frac{1}{2}} \mid\left(\frac{x}{A}\right)^{4}\right]=A \cdot \operatorname{sn}^{-1}\left(\frac{|x|}{A} \mid-1\right)=C+\frac{\left|c_{3}\right| A^{2}}{\sqrt{2}} t .
$$

Since the initial condition $x(0)=A$, we conclude

$$
C=A \mathrm{sn}^{-1}(1 \mid-1)=A \cdot K(-1),
$$

where $K(m)=F\left(\frac{\pi}{2} \mid m\right)$ denotes the complete elliptic integral of the first kind. The Jacobi elliptic sn $(z \mid m)$ has the period $4 K(m)$, so

$$
4 K(-1)=\mathrm{B}=\left(\frac{1}{4}, \frac{1}{2}\right) \frac{\Gamma^{2}\left(\frac{1}{4}\right)}{\sqrt{2 \pi}} \approx 5.244116,
$$

is the period of the function sn $(z \mid-1)$. Employing the quarter-period transformation formula for the Jacobi amplitude (Web1):

$$
\operatorname{am}(K(m)-z \mid m)=\frac{\pi}{2}-\operatorname{am}\left(\sqrt{1-m} z \mid \frac{m}{m-1}\right), \quad m \leq 1
$$

for $m=-1$, one deduces by that

$$
\begin{aligned}
x(t) & =A \operatorname{sn}\left(K(-1)+\frac{\left|c_{3}\right| A}{\sqrt{2}} t \mid-1\right)=A \sin \operatorname{am}\left(K(-1)+\frac{\left|c_{3}\right| A}{\sqrt{2}} t \mid-1\right) \\
& =A \sin \left\{\frac{\pi}{2}-\operatorname{am}\left(K(-1)+\frac{\left|c_{3}\right| A}{\sqrt{2}} t \mid-1\right)\right\}=A \cos \operatorname{am}\left(\left|c_{3}\right| A t \mid \frac{1}{2}\right) .
\end{aligned}
$$

Thus

$$
x(t)=A \operatorname{cn}\left(\left|c_{3}\right| A t \mid \frac{1}{2}\right)
$$

Here $\operatorname{cn}(z \mid m)=\cos \operatorname{am}(z \mid m)$ denotes the Jacobi elliptic cn function. It is worth saying that Lyapunov in his classical paper (Lyapunov 1893) introduced the Jacobi elliptic functions (cn and sn) which are the special case of Ateb Cosine and Ateb Sinus functions for $\alpha=3$. The same functions are used for solving the third order nonlinear differential equation of Duffing type by Yuste and Bejarano (1990), but also Chen and Cheung (1996), and Kovacic et al. (2016).

By using Eq. (2), the solution given by Eq. (58) and (41) corresponding to $C_{3}=1$ and $A=1$ can be expressed as

$$
x(t)=c a(3,1, \sqrt{2} t)
$$




$$
\begin{aligned}
x(t)=\approx & 0.95501 \cos (0.84721 t)+0.04305 \cos (2.54164 t)+ \\
& 0.00186 \cos (4.23607 t)+0.00008 \cos (5.93049 t) .
\end{aligned}
$$

The content is such that the first harmonic dominates with $95 \%$ in the response, the third one takes around $4 \%$ of it and the rest of them are again very smaller. All the Fourier coefficients calculated are positive.

\section{Forced response}

\subsection{Design of excitation and derivation of amplitude-frequency equation}

This section is concerned with purely nonlinear oscillators externally excited by the force $F$ :

$$
\ddot{x}+c_{\alpha}^{2} x|x|^{\alpha-1}=F .
$$

The question of interest here is the way how $F$ should change with time explicitly so that Eq. (61) has the exact closed-form solution for the corresponding forced response. To answer this, the excitation is assumed as

$$
F=\frac{F_{0}}{A|A|^{\alpha-1}} x|x|^{\alpha-1},
$$

as a result of which the equation of motion (61) turns into

$$
\ddot{x}+\left(c_{\alpha}^{2}-\frac{F_{0}}{A|A|^{\alpha-1}}\right) x|x|^{\alpha-1}=0 .
$$

Comparing it with Eq. (2), which solution is given by Eq. (41), one concludes that Eq. (63) has the solution

$$
x=A \operatorname{ca}\left(\alpha, 1, \omega_{r} t\right)
$$

where

$$
\omega_{r}=|A|^{(\alpha-1) / 2} \sqrt{\frac{\alpha+1}{2}\left(c_{\alpha}^{2}-\frac{F_{0}}{\operatorname{sgn}(A)|A|^{\alpha}}\right)},
$$

under the condition that the radicand is positive.

This implies that the required form of the force (62) is given by:

$$
F=F_{0} \operatorname{ca}\left(\alpha, 1, \omega_{r} t\right)\left|\operatorname{ca}\left(\alpha, 1, \omega_{r} t\right)\right|^{\alpha-1} .
$$

Based on the results presented in Section 3.2, one can interpret this excitation as a multiterm harmonic excitation with odd harmonics which amplitudes and frequencies are mutually related.

The sought autonomous equation of motion is, then:

$$
\ddot{x}+c_{\alpha}^{2} x|x|^{\alpha-1}=F_{0} \operatorname{ca}\left(\alpha, 1, \omega_{r} t\right)\left|\operatorname{ca}\left(\alpha, 1, \omega_{r} t\right)\right|^{\alpha-1} .
$$

The expression (65) can further be transformed into the following amplitude-frequency equation: 


$$
-\frac{2}{\alpha+1} \omega_{r}^{2} A+c_{\alpha}^{2} A|A|^{\alpha-1}=F_{0} .
$$

For some given values of $F_{0}$ and $c_{\alpha}^{2}$, Eq. (68) enables one to find the amplitude(s) corresponding to different values of the frequency $\omega_{r}$ and to plot frequency-response (amplitude-frequency) curves. The branches of this curve will be located around the backbone curves. The relationship for it can be obtained from Eq. (68) with $F_{0}=0$ :

$$
\omega_{b c}=|A|^{(\alpha-1) / 2} \sqrt{c_{\alpha}^{2} \frac{\alpha+1}{2}},
$$

which is in agreement with the frequency existing in Eq. (41).

To find the value of frequency at which the number of possible solutions changes, i.e. where the saddle-node (SD) point occurs, one can differentiate Eq. (68) with respect to $A$ to derive

$$
\omega_{r}^{2}=|A|^{\alpha-1} c_{\alpha}^{2} \frac{\alpha(\alpha+1)}{2} .
$$

Substituting this back into Eq. (68) and then into Eq. (70), one can derive the following expressions for the amplitude $|\hat{A}|$ and frequency $\hat{\omega}_{r}$ at which the SD point exists

$$
\begin{gathered}
|\hat{A}|=\left[\frac{F_{0}}{c_{\alpha}^{2}|\alpha-1|}\right]^{1 / \alpha}, \\
\hat{\omega}_{r}=\sqrt{\frac{c_{\alpha}^{2} \alpha(\alpha+1)}{2}}\left[\frac{F_{0}}{c_{\alpha}^{2}|\alpha-1|}\right]^{\frac{\alpha-1}{2 \alpha}} .
\end{gathered}
$$

Figure 2 shows the rescaled SD amplitudes $\left|A^{*}\right|=|\hat{A}| /\left(\frac{F_{0}}{c_{\alpha}^{2}}\right)^{1 / \alpha}$ and the frequency $\omega_{r}^{*}=\hat{\omega}_{r} /\left(c_{\alpha}\left(\frac{F_{0}}{c_{\alpha}^{2}}\right)^{\frac{\alpha-1}{2 \alpha}}\right)$ versus the power of nonlinearity $\alpha$. These graphs can be used to estimate where the point SD occurs depending on the power $\alpha$.
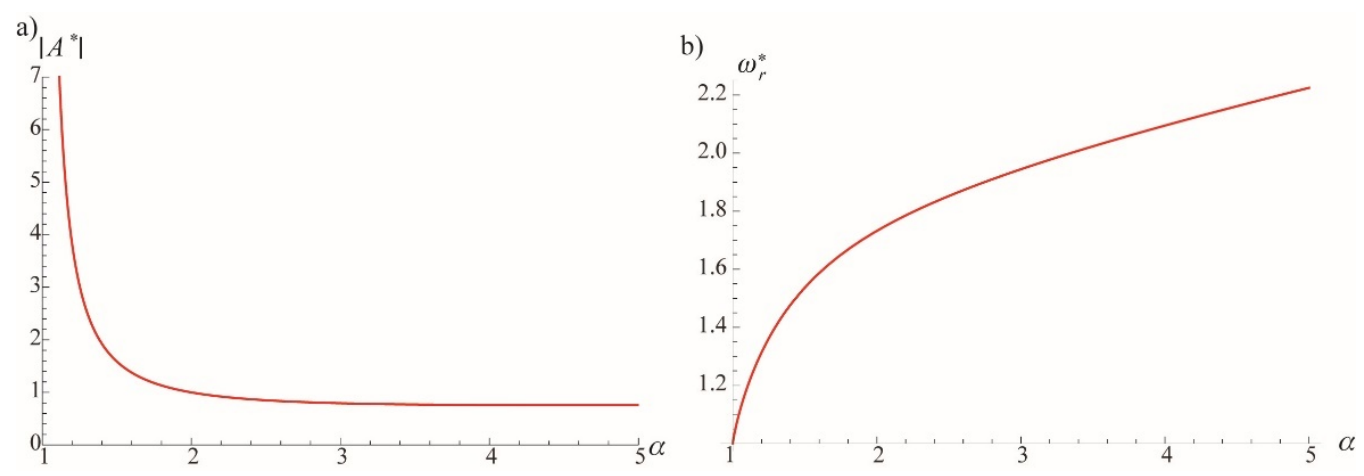

Fig. 2. a) Graph of the rescaled SD amplitudes $\left|A^{*}\right|$ versus the power of nonlinearity $\alpha$; b) Graph of the rescaled SD frequency $\omega_{r}^{*}$ versus the power of nonlinearity $\alpha$ 


\subsection{Special cases}

\subsubsection{Case $\alpha=1$}

In the linear case, Eq. (67) reduces to the harmonically excited linear oscillator

$$
\ddot{x}+c_{1}^{2} x=F_{0} \cos \left(\omega_{r} t\right) \text {. }
$$

where

$$
\omega_{r}=\sqrt{c_{1}^{2}-\frac{F_{0}}{A}} .
$$

with the forced response being

$$
x=A \cos \left(\omega_{r} t\right)
$$

Indeed, it is easy to check that Eq. (75) satisfies Eq. (73).

\subsubsection{Case $\alpha=2$}

For purely nonlinear oscillators with odd quadratic nonlinearity, Eq. (67) transforms now into

$$
\ddot{x}+c_{2}^{2} \operatorname{sgn}(x)|x|^{2}=F_{0} \operatorname{sgn}\left(\operatorname{ca}\left(2,1, \omega_{r} t\right)\right)\left|\operatorname{ca}\left(2,1, \omega_{r} t\right)\right|^{2} .
$$

Its solution is

$$
x=A \operatorname{ca}\left(2,1, \omega_{r} t\right)
$$

where

$$
\omega_{r}=\sqrt{\frac{3}{2}|A|\left(c_{2}^{2}-\frac{F_{0}}{\operatorname{sgn}(A)|A|^{2}}\right)},
$$

Equation (68) is used to plot the frequency-response branches in Fig. 3a for $c_{2}=1$ and $F_{0}=1 / 2$.
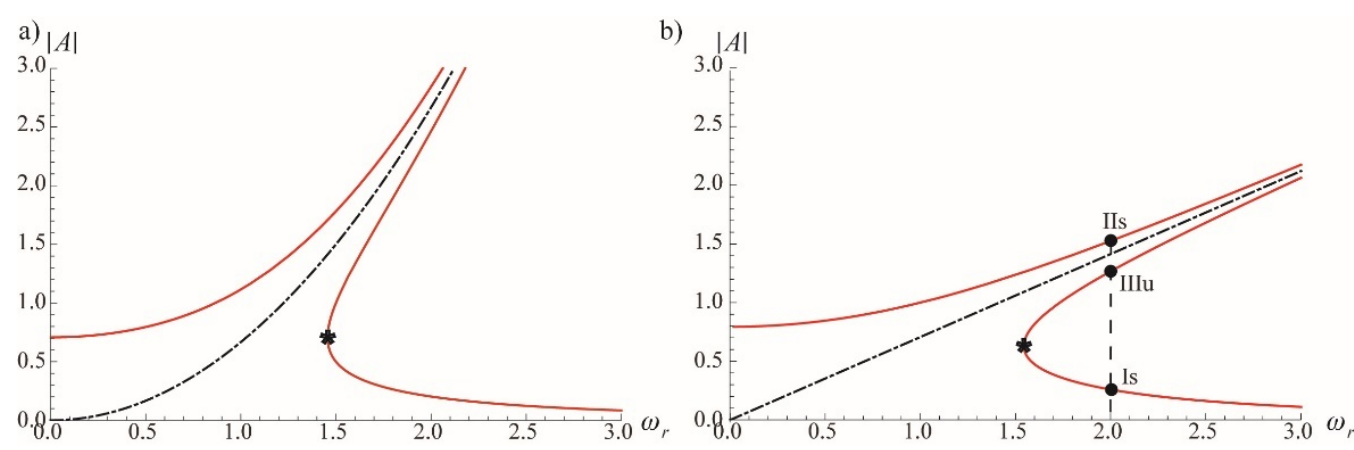

Fig. 3. Frequency-response curves (solid line), the SD point (asterix) and the backbone curve (dashed-dotted line) corresponding to $C_{\alpha}=1, F_{0}=1 / 2$ and: a) $\alpha=2$; b) $\alpha=3$ 
The backbone curve (70) is also presented and the SD point is labelled by the asterix. The frequency-response branches are bent to the right-hand side and there is a frequency region in which a multi-valued response exists.

\subsubsection{Case $\alpha=3$}

For the pure cubic case, Eq. (67) becomes

$$
\ddot{x}+c_{3}^{2} x^{3}=F_{0} \mathrm{ca}^{3}\left(3,1, \omega_{r} t\right) .
$$

The exact closed-form solution for the forced response is

$$
x=A \operatorname{ca}\left(3,1, \omega_{r} t\right)
$$

with

$$
\omega_{r}=|A| \sqrt{2\left(C_{3}^{2}-\frac{F_{0}}{A^{3}}\right)} .
$$

The corresponding frequency-response curve is plotted in Fig. $3 \mathrm{~b}$ for $c_{3}=1$ and $F_{0}=1 / 2$. To illustrate the time history, the case $\omega_{r}=2$ is considered (Fig. 3b). Three values of the amplitude are calculated from Eq. (68). Two stable ones are labelled by Is and IIs: $A_{\mathrm{ls}}=$ 0.258652 and $A_{\text {IIs }}=1.52569$. The third one is unstable: $A_{\text {IIIu }}=-1.26704$. The details about the stability check are omitted here, as this was done in a classical way by introducing the perturbation into the equation of motion (61), and deriving the linear variational equation (Rand 2016). The solution for the forced response was used as the Fourier series (see Section 3.2):

$$
\begin{gathered}
x_{\mathrm{Is}}=-0.25865 \mathrm{ca}(3,1,2 t) \\
x_{\mathrm{Is}} \approx-0.24701 \cos (1.19814 t)-0.01113 \cos (3.59442 t)- \\
0.00048 \cos (5.9907 t)-0.00002 \cos (8.38698 t),
\end{gathered}
$$

and

$$
\begin{gathered}
x_{\text {IIs }}=1.52569 \mathrm{ca}(3,1,2 t), \\
x_{\text {IIs }} \approx 1.45704 \cos (1.19814 t)+0.06568 \cos (3.59442 t)+ \\
0.00284 \cos (5.9907 t)+0.00012 \cos (8.38698 t) .
\end{gathered}
$$

Hill's equation was obtained subsequently for all the solutions. The corresponding positions in the stability chart with respect to the instability tongues were analysed (Rand 2016) to detect whether the solutions found are stable or unstable.

Two pairs of stable solutions are shown in Fig. 4 together with the numerical solutions of Eqs. (79) and (81) to demonstrate their mutual agreement. 
a)

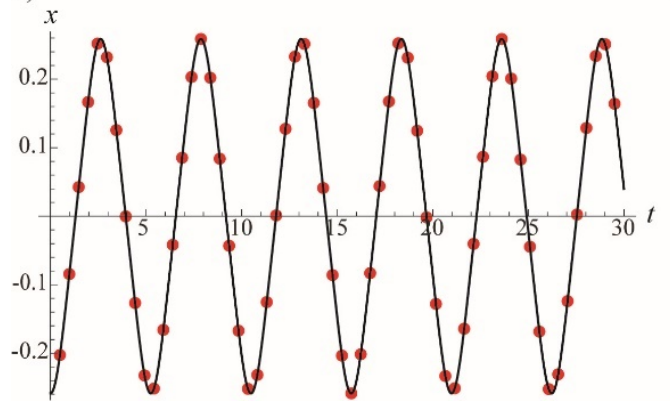

b)

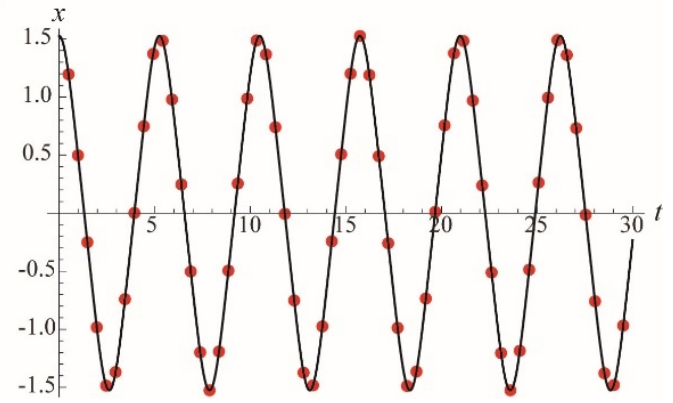

Fig. 4. Time response corresponding to $c_{3}=1$ and $F_{0}=1 / 2, \alpha=3, \omega_{r}=2$ and: a) Case Is from Figure 3b); a) Case IIs from Figure 3b). The numerical solution of Eqs. (79) - red dots, Fourier series approximations, Eqs. (83), (85) - black solid line

\section{Conclusions}

The exact solutions for purely nonlinear oscillators with one-degree-of-freedom have been overviewed. It has been shown how their period of free vibration can be expressed in terms of special functions, such as the beta and gamma function, and also as a function of the initial amplitude, coefficient of nonlinearity and the power of nonlinearity. This has also been done for the case when the constant excitation acts. Further, it has been demonstrated how the free response of these oscillators with the power of nonlinearity higher than unity can be expressed in terms of Ateb functions and how it transforms into the Jacobi cn function when the oscillator is cubic. Forced vibrations have been considered as well, and the external excitation designed to yield the closed-form solution in terms of the Ateb function. Frequency-response curves have been presented to illustrate the response in the frequency domain and the forced vibrations in the time domain.

Acknowledgements The authors acknowledge the support of the Ministry of Education, Science and Technological Development of Serbia, Project No. ON174028.

Извод

\section{Тачна решења за чисто нелинеарне осцилаторе: преглед}

\section{Л. Цветићанин ${ }^{1}$, И. Ковачић ${ }^{1 *}$}

${ }^{1}$ Универзитет у Новом Саду, Факултет техничких наука, Центар за вибро-акустичке системе и обраду сигнала ЦЕВАС

имејл: cveticanin@uns.ac.rs

имејл: ivanakov@uns.ac.rs

*главни аутор

\section{Резиме}


Овај рад даје преглед тачних аналитичких решења у затвореној форми за чисто нелинеарне осцилаторе. Ова решења обухватају период осциловања, као и решења за слободне и принудне осцилације система са једним степеном слободе кретања. У ову сврху, коришћене су специјалне функције: бета функција, гама функција, хипергеометријска функција, Атеб функција, Јакобијева амплитуда и Јакобијева елиптичка функција.

Кључне речи: чисто нелинеарни осцилатори, слободни одговор, принудни одговор, Атеб функција, Јакобијева елиптичка функција

\section{References}

Beléndez A, Francés J, Beléndez T, Bleda S, Pascual C, Arribas E (2015). Nonlinear oscillator with power-form elastic-term: Fourier series expansion of the exact solution, Communications in Nonlinear Science and Numerical Simulation, 22, 134-148.

Chen SH, Cheung YK (1996). An elliptic perturbation method for certain strongly non-linear oscillators, Journal of Sound and Vibration, 192, 453-464.

Chen WH, Gibson RF (1998). Property distribution determination for nonuniform composite beams from vibration response measurements and Galerkin's method, Journal of Applied Mechanics, 65, 127-133.

Colm IJ, Clark NJ (1988). Forming, Shaping and Working of High-Performace Ceramics, Blackie, New York (1988)

Cveticanin L (2009). Oscillator with fraction order restoring force, Journal of Sound and Vibration, 320, 1064-1077.

Cveticanin L (2011). Pure odd-order oscillators with constant excitation, Journal of Sound and Vibration, 330, 976-986.

Cveticanin L, Pogany T (2012). Oscillator with a sum of non-integer order non-linearities, Journal of Applied Mathematics, art. no. 649050, 20 pages.

Cveticanin L (2014). Strongly Nonlinear Oscillators -Analytical Solutions, Springer, Berlin.

Gottlieb HPW (2003). Frequencies of oscillators with fractional-power non-linearities, Journal of Sound and Vibration, 261, 557-566.

Gradshtein IS, Rjizhik IM (1971). Tablici Integralov, Summ, Rjadov i Proizvedenij, Nauka, Moscow.

Haslach HW (1985). Post-buckling behavior of columns with nonlinear constitutive equations, International Journal of Non-Linear Mechanics, 20, 53-67.

Haslach HW (1992). Influence of adsorbed moisture on the elastic post-buckling behavior of columns made of non-linear hydrophilic polymers, International Journal of Non-Linear Mechanics, 27, 527-546.

Kovacic I, Cveticanin L, Zukovic M, Rakaric Z (2016). Jacobi elliptic functions: A review of nonlinear oscillatory application problems, Journal of Sound and Vibration, 380, 1-36.

Lewis G, Monasa F (1982). Large deflections of a cantilever beams of nonlinear materials of the Ludwick type subjected to an end moment, International Journal of Non-Linear Mechanics, 17, 1-6. 
Lo CC, Gupta SD (1978). Bending of a nonlinear rectangular beam in large deflection, Journal of Applied Mechanics, 45 213-215.

Lyapunov AM (1893). An investigation of one of the singular cases of the theory of the stability of motion, II. Mathematicheskiy Sbornik, 17, 253-333 (in Russian).

Patten WN, Sha S, Mo C (1998). A vibration model of open celled polyurethane foam automative seat cuchions, Journal of Sound and Vibration, 217 145-161.

Prathap G, Varadan TK (1976). The inelastic large deformation of beams, Journal of Applied Mechanics, 43 689-690.

Rand RH (August 2016). Lecture Notes on Nonlinear Vibrations (version 53), http://dspace.library.cornell.edu/handle/1813/28989.

Rosenberg R (1963). The ateb(h)-functions and their properties, Quarterly of Applied Mathematics, 21, 37-47.

Rosenberg RM (1966). On nonlinear vibrating systems with many degrees of freedom, Advances in Applied Mechanics, 32, 155-242.

Senik PM (1969). Inversion of the incomplete Beta function, Ukrainian Mathematical Journal, 21, 271-278.

Yuste BS, Bejarano JD (1990). Improvement of a Krylov-Bogoliubov method that uses Jacobi elliptic functions, Journal of Sound and Vibration, 139, 151-163.

Web1: http://functions.wolfram.com/GammaBetaErf/Beta3/26/01/02/0001

Web2: http://functions.wolfram.com/HypergeometricFunctions/

Hypergeometric2F1/03/09/19/02/0017

Web3: http://functions.wolfram.com/EllipticIntegrals/EllipticF/16/01/02/0001

Web4: http://functions.wolfram.com/HypergeometricFunctions/

Hypergeometric2F1/03/07/17/01/0012 